\title{
User experience of a web-based platform for poultry market linkages in Tanzania
}

\author{
Cesilia Mambile $^{1^{*}}$, Dina Machuve ${ }^{2}$ and Sabine Moebs ${ }^{3}$ \\ Masters Candidate, Department of Information Communication Science and Engineering, Specializing in \\ Information Technology Systems Development and Management at Nelson Mandela African Institution of Science \\ and Technology, Arusha Tanzania ${ }^{1}$ \\ Lecturer, Nelson Mandela African Institution of Science and Technology (NM-AIST), Tanzania ${ }^{2}$ \\ Professor, Baden-Württemberg Cooperative State University, Germany ${ }^{3}$
}

\section{(C)2018 ACCENTS}

\begin{abstract}
In Tanzania the advancement of technology has brought about affordable smartphones to most of livestock farmers. However, despite this potential, livestock farmers have limited utilization and access to livestock information systems to improve their business. Poultry farming has business potential in Tanzania but farmers in the sector are challenged on reliable market linkage information systems to interface with buyers for their products. Poultry farmers are equally challenged on limited exposure to technology. The aim of this study was to develop a web-based platform for poultry market linkage with more focus on its usability and user experience $(U X)$ design and assessment of the user experience. Eye tracking method combined with retrospective thinks aloud method together with facial expression was used to test user experience of the developed web-based platform. The results on eye tracking experiment for user experience indicated that users were emotionally happy when performing two tasks; 1) finding posts for advertisements on poultry and poultry products and 2) obtaining more information on advertised products. Users struggled on tasks for creating account on the web-based platform as well as purchasing items online on the platform. It is now more important than ever before that web applications provide a good user experience which was once considered luxury or an added expense.
\end{abstract}

Keywords

UX, UX design, Web based platform, Farmers and buyers, Market linkage, Market information.

\section{Introduction}

In Tanzania, there are several livestock web applications such as livestock information network and knowledge system (LINKS), Tanzania livestock identification and traceability system (TANLITS) and Green planet livestock, developed for livestock farmers to provide them with various information, such as market information, poultry feeds information, poultry health and livestock breeding. This could imply that these websites have significant impact on livestock farming aspects of our society [1, 2]. As we all know that web applications play a significant role in the success of business $[1,2]$. But there is a gap; these existing websites lack user experience (UX) and usability tests.

\footnotetext{
*Author for correspondence
}

This work was supported in part by the DAAD Scholarship at NMAIST, Arusha, Tanzania in 2017 to 2018.
Despite the fact that advancement of technology has brought affordable smartphones to most of the livestock farmers, potential livestock information systems in Tanzania are used by very few livestock farmers and some of these systems are not used at all [3].

It is not that users do not need the system, nor the system does not show any potential for them, but depend on its usability and how well it suited to the user requirements based on their differences. Users of the system have a lot of differences including exposure to technology [4]. For example, the results obtained during the study conducted by Mussa et al., 2016 [3] to evaluate the usability and users satisfaction of the livestock information network knowledge system (LINKS) indicate that information targeting and access in LINKS was not well planned, since the access of information from LINKS is mainly through short message service (SMS), community information centre, email, newspaper, television and radio. All these methods said favour 
buyers than farmers because buyers have easy access and more capabilities of using technology, while the primary target of LINKS was farmers. So the development was not user centred, therefore it resulted in an ineffective system and a lack of user satisfaction, which means bad user experience.

Studies conducted by [3] and [1] shows that most of web applications are still being built with Ad hoc methods which focus more on presentation aspects. This method does not consider UX design and usability, and this result to web applications that do not meet user needs and not interesting either. Being both usable and interesting, a web application might be regarded as appealing and as a consequence the users will enjoy using it [5]. Therefore, it is important to develop these web based applications for farmers in Tanzania with high degree of usability, functionality and user experience. The success of any application depends on how well it is being used by users and how well it is suited to the users' requirements based on their experience $[4,6]$.

According to [7] and [8], users' experience is the overall effect or feeling created by the interaction and perceptions that someone has when using a website, mobile device, service or software. Defined user experience as meaningful personally encountered events. In order to reach more unified standardized definition of UX, The international organization of standardization (ISO 9241-210, 2010) defines the term user experience as a "person's perception and response resulting from the use and/or anticipated use of product, system or service". User experience is a balance between the ability of the product to provide the user with task related needs and the ability of the product to provide the user with needs that are not task related needs such as stimulation and emotional effect when interacting with a product.

This work intends to address the importance of consideration of UX in designing web based platform for poultry farmers and buyers in Tanzania since the available livestock websites lack UX and usability. An intention behind this work is to motivate the development of web applications in Tanzania with the real users in mind, which can help ensure that each system suits user needs [7], task related needs (usability) and non-task related needs (visual appearing).

The first part of this work gives brief introduction whereas the second part introduces the problem and also discusses the need of user experience in Tanzania. The third part is to bring user experience design to web based platform for reliable market linkage between poultry farmers and potential buyers in Tanzania. Followed by the actual implementation, user experience testing experiment design, results and lastly conclusion and recommendation. Figure 1 shows the block diagram of the study work.

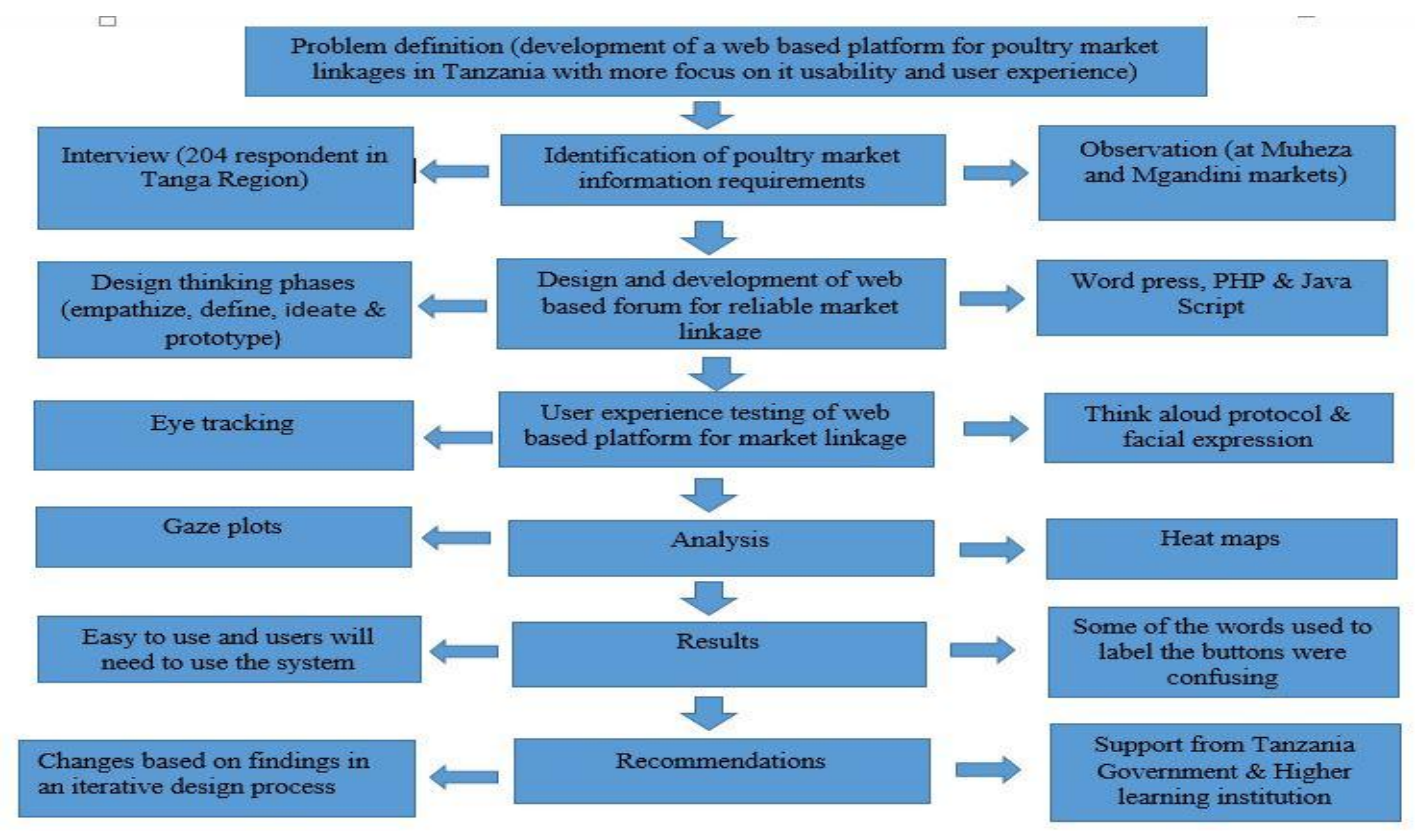

Figure 1 Block diagram of the study work, 2018 


\section{Material and methods}

2.1User experience considerations in system development in Tanzania

It is now as more important than ever that web applications provide a good user experience which was once considered luxury or an added expenses [8, 9]. Even most successful firms in the world like Google, iPhone and Amazon now recognize that focusing on user experience is a key to achievement and novelty $[8,10]$. Systems in Tanzania need user experience design, since it makes technology accessible and usable for intended users. Good UX design caters specifically to the needs of the two very distinct groups of this study, farmers and buyers. It allows creation of a web application that nurture people's independence, intelligence and dignity [7, 9]. In comparison to developed countries, Tanzania we should also think big that UX design can enhance the growth of the livestock industry. Due to the tremendous growth of technology and business all over the world, it is increasingly recognized that having an app or website with an intuitive and functional user experience is not only crucial to customer happiness and satisfaction, but also key to profitability [11]. UX design builds the value of the business, since it can lead to happier users, fewer complaints, more sales and higher profit also elevates customer's perception of the entire brand $[8,11]$. UX design helps people to derive pleasure (enjoyment) from the time they spend using technology. Furthermore UX design could help in emergency situations, for example in clinical setting good UX could help to find important information quickly and avoid mistakes.

Neglecting UX can result to sloppy site that people will never come back to. Developing an interaction rich experience can derive people back to the site. UX design is deeply human centric, great UX design happen when you talk to users and solve their problem.

2.2User experience design in web based platform for reliable poultry market linkage

Developing a web based platform to link the poultry farmers with the potential buyers with more focus on usability and user experience is an opportunity. Poultry farming has a very good business potential [12]. Chicken are fast growing animals meaning the business has potential to generate high return on investment under a short period of time. For example past days it took about four months for a chicken to become two kilograms, however these days a two kilogram chicken can be produced within 42 days
[13]. There is high demand of poultry and poultry products, e.g. meat and eggs are in higher demand especially in urban and peri-urban areas by individual persons, restaurants, hotels, industries etc. Due to increased health awareness about the red meat, chicken have been considered to be a great alternative.

Advertising through Television, Radio and Brochure is expensive and it is of limited distance coverage. Also advertising through friends is not a way that someone could rely on. People will look for something cheap but which enables them to advertise in wide context. Larger percentage of people hang around the internet these days and internet has become available and affordable hence continue expansion of online sales. In order for poultry farmers to succeed in their business it will reach a time when it will become impossible for them to close their eyes on the internet.

There are various approaches to designing great user experience, because user experience don't happen by chance, they are created through user experience design process. Developing new products with better UX requires the participation of various stakeholders including real users $[9,10,14]$. User involvement is especial important in order to identify the user's needs, requirements, capabilities, understanding what emotions are important for them in interaction and anticipate their expectations [7, 9]. In fact user participation is considered as one of the key principles of user centered design and has several benefits such as achieving usability and accessibility. There are so many processes or frameworks for user experience design life cycle and they can be a great place to start designing user experience [7, 14]. For example there is Toddy Zaki Warfel framework which gives a good sequential over view of the activities that are conducted in typical user centered design process with functional design phase, content analysis phase, interaction design and information architecture phase and engineering phase. There is also David Armano framework with uncover, define, ideate, build and design phases, this framework also is good because it help you think about the higher level goals of each phase. From these two examples and others from Stephen P. Anderson, James Kelway etc. you will find there are standard set of activities and deliverables that are common to all like user centered design and usability testing. Someone will just need to understand this and then choose which model will suit him in the work that he is doing. 
In order to consider good user experience design for farmers (less exposed to technology) and buyers (more exposed to technology), the UX design model life cycle introduced by [15] was used. This model was selected simply because it is simple unlike others which are confusing and complex. The four stages of this model suits well when designing new website. According to this model there are four elemental UX activities or stages: analyze, design, prototype and evaluation. We bring the UX design in web-based platform for reliable market linkage between farmers and buyers by focusing on users and the model.

The first stage (analysis phase) was understanding the poultry farmers and buyers work and needs by listening to them, observing them in their natural habitat, create personas and emphasize with them $[14,15]$. This stage was necessary for understanding user's needs, requirements, capabilities and expectation. In this stage wireframes, use cases, Data flow Diagrams were created. Design to serve the business goals by serving user goals was the key concern $[8,9,16]$. In the second stage, prototyping (implementation) the conceptual design was formulated into prototypes and implemented [15, 16]. The implementation stage was explained in details in section 2.3. And the last phase was evaluating the design with users by conducting user experience testing to see if the design meets great user experience, user needs and requirements. Finally making changes based on the finding in an iterative design process $[8,15,16]$. The user experience testing conducted in this study is discussed in detail in section 2.4 of this paper.

\subsection{The actual implementation}

Often implementation does not start from scratch. Most of the time we review other sites to see what they are doing, since there is always a research on what has worked or failed. Developing from scratch always is so closetful in terms of money and time; perhaps it will be very difficult to have all the functionalities together with good user experience. To reuse the software to build customized solution for users makes it able to capture important benefit such as increased productivity and customer production. Also traditionally businesses in developing countries, similarly in developed countries are hindered by a small budget and limited technical expertise [17]. In order to save time and money while achieving good quality and user experience, open source software was used in this study to implement the web based system for market linkage between farmers and buyers.
There are a variety of online open source software for website creation like Word press, Joomla, Drupal, Mangeto, Blogger, Bitrix, Adobe Dreamwever etc. All are open source and differ significantly in terms of features, flexibility, capabilities and ease of use. In this study Word press an online open source website creation tool based in hypertext pre-processorr (PHP) and MySQL, was used to develop Web based platform for Reliable Market Linkage between Farmers and Potential Buyers.

Word press has been chosen to develop this platform because of the power of plugin, which allow easy customization and modification. It have application program interface (APIs) that make it possible for users to create own plugins and extend functionality. Word press has a very powerful, vibrant and supportive community [18, 19]. In addition word press support more than 60 languages. Also it has very easy way for users to manage contents, drafts, private or public posts, the widgets are designed to provide simple and easy way of structuring, designing and creating pages without using the technical platform of hypertext mark-up language (HTML). It is easy to create look and feel and keep the website fresh by changing the site layout by clicking single button. It has very responsive theme that automatically adjust to fit into mobile screen, no need to create a separate website for mobile phones. Furthermore Word press codes are very easy to index via Google [18, 19].

The developed web-based platform for market linkage is simple and not overloaded by information. All the required market information (farmer's location, price, amount of poultry and poultry product, kind of poultry product and type of poultry) is available in the platform since all poultry farmer and buyers before advertising products and needs will be required to register first. Buyers upon selecting a particular product all the details regarding that product will be shown. Buyers (farmers, individual person, shops, catering services, supermarkets, hotels, industries, butchers and other farmers) can make orders and purchase poultry and poultry products form the platform. Each poultry farmer and buyer will be able to view and manage his orders. Through administrator farmers can do auctions. This web based platform also provides poultry industry information such as poultry diseases and feeds. The web based platform available in English also in Swahili. Figure 2 shows the interface of the web based platform for market linkage between poultry farmers and potential buyers. 


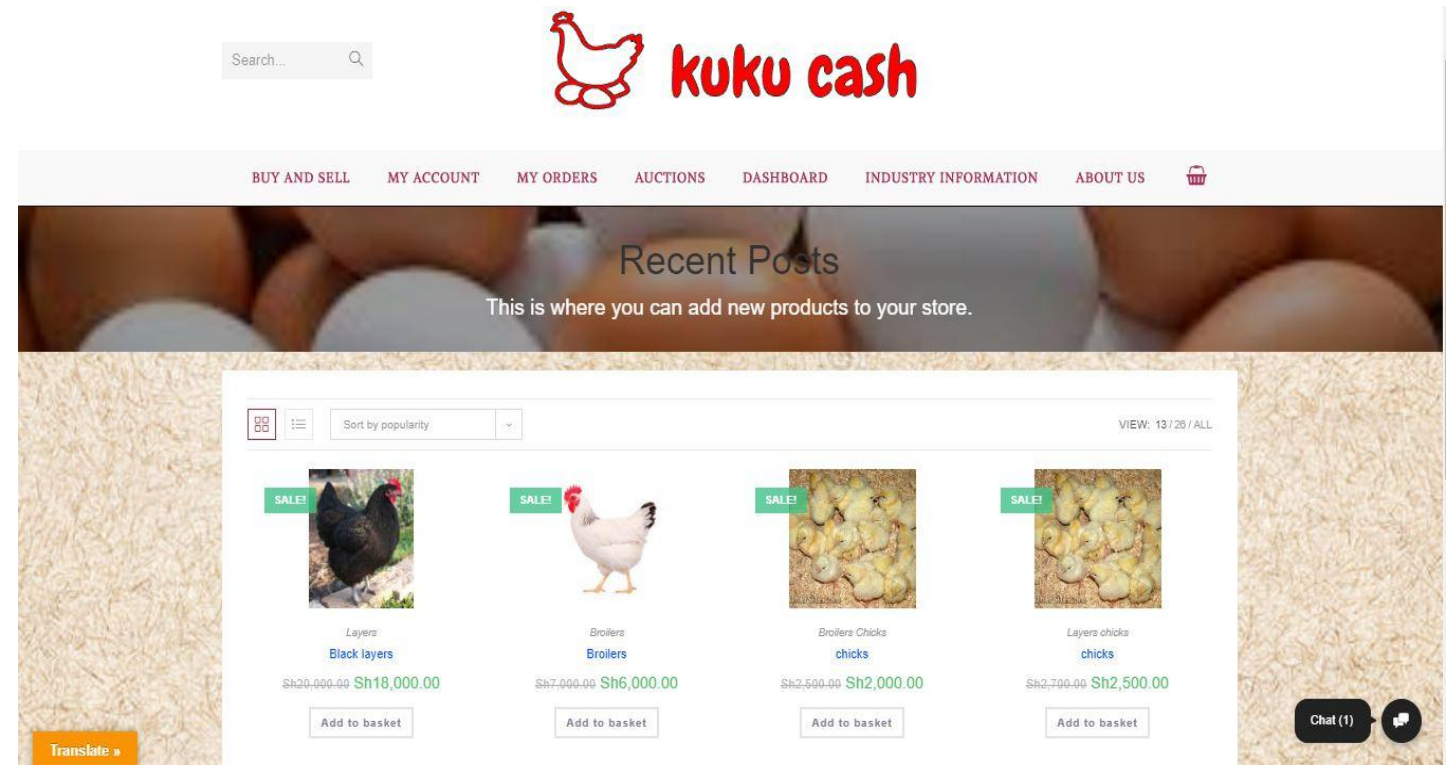

Figure 2 Interface of the web based platform for market linkage between poultry farmers and potential buyers in Tanzania, 2018

\subsection{User experience testing experiment design}

In this study eye tracking method combined with retrospective think aloud method and facial expression was used to test user experience of the developed web based platform. The platform was tested through evaluating the effectiveness of the developed web interface by examining emotional behaviour. If the interface, for example the home interface fails to clearly state what the website offers and what users can do on the site, people will leave" [20].

To study the user experience of this web application the population was poultry farmers. Simple random sampling method together with screening questionnaire was used to select participants. The study was held at the period of June to July 2018. The participants were between 18 and 65 years old. The total sample size was 5 participants. The user experience test includes four tasks whereby each participant performs all the tasks. The task requires the participant to create account, to find if someone has posted (advertisement) information about poultry and poultry products before you decide to buy, to find out where you can find more information about the advertised products, and to try to buy 20 eggs from the website. User experience was evaluated with the version of web based application (high fidelity prototype). During the session's participants was given short introductory statement to lead to the subject that explains the purpose and procedure for the test. A pre-test questionnaire was conducted. Table 1 shows the poultry buyers task scenario.

\section{Task/Scenario}

Test participants attempted completion of the following tasks

Table 1 Poultry buyers task scenario

\begin{tabular}{lll}
\hline & \multicolumn{1}{c}{ Tasks } & $\begin{array}{l}\text { Estimated } \\
\text { (MIN) / baseline }\end{array}$ \\
\hline Task 1 & Create account & $5 / 3$ \\
Task 2 & $\begin{array}{l}\text { Find if someone has posted (advertisement) information about poultry and poultry } \\
\text { products before you decide to buy. }\end{array}$ & $5 / 3$ \\
& Find out where you can find more information about the advertised products & $5 / 3$ \\
Task 3 & Try buying 20 eggs from this website & $7 / 5$ \\
\hline
\end{tabular}

While the user was performing tasks observation was made and detailed notice taken. The participants were asked to complete post testing questionnaire system usability scale (SUS) to measure different aspects of user experience. Figure 3 below is user experience test model. 
Mambile et al.

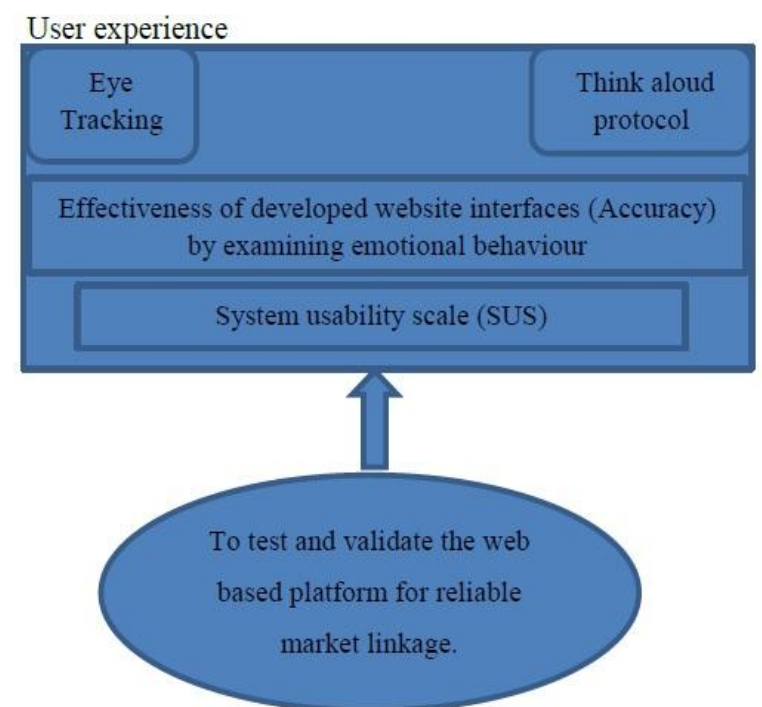

Figure 3 User experience test model

\section{Results}

The data was analyzed using gaze plots and heat maps for user's entire visit to web based platform for market linkage together with think aloud data and facial expression and draw conclusion from these data. Gaze plots and heat maps are useful because they give important data like which areas of the screen draw users' attention and the order sequence in which content is viewed. Figure 4 and 5 below shows Heat map and Gaze plot images of some of users.

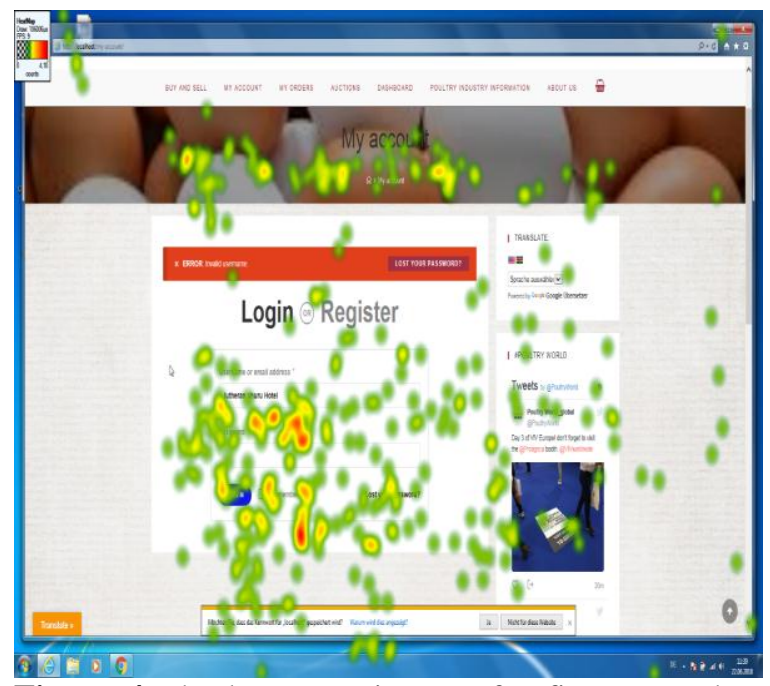

Figure 4 The heat map image of a first user when interacting with web based platform for market linkage, 2018

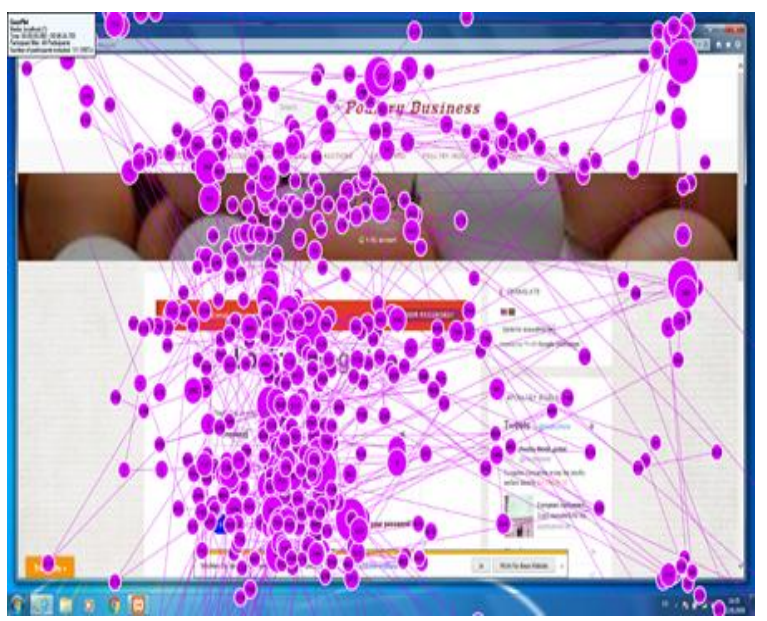

Figure 5 The gaze plot image of a last user when performing the tasks, 2018

Gaze plots and heat maps for all 5 users were analysed and the results show that a larger amount of attention was paid to the login page and checkout page of the website. People also look a little bit to menu items. There is a smaller amount of attention to the right side of the website and there is almost no fixation (attention) to the right side of the website. These results shows that user spend a lot of time during creating account and during the checkout process, while spend little time on other parts of the website.

During the testing sessions participants were also asked to think out loudly. Testing administrator was taking detailed notes and record participant's behaviour including the facial expression of each participant during testing sessions.

The data from eye tracking think aloud protocol and facial expression was combined together. The result shows that users were emotionally happy when performing the second and the third tasks. But when performing the first task and the last task users were emotionally anxiety and disappointed. The eye tracking data (gaze plots and heat maps) shows that, users spend a lot of time when performing the first and the last tasks. Most of the think aloud data shows that, the users was wondering what to do when performing the first task and the last task. Also facial expression data shows the participants were not emotionally happy when performing the first and the last tasks. The values in Table 2 have been calculated as follows: the total numbers of participants during testing were five, each person carries $20 \%$ of agree (strong agree or agree) or disagree (strong disagree or disagree). So counting percentage agree (strong agree 
or agree), just sum up the number in these two columns (strong agree or agree). If you get 4 then is equal to $80 \%$ etc.

The majority of participants $(80 \%)$ agreed (agree or strong agree) they would use the website frequently. Most of the participants $(60 \%)$ agreed the website was easy to use.

$60 \%$ of the participants think that most people would learn to use the system very quickly and could become productive using this system. All participants (100\%) would like to recommend this website to a friend. Only $40 \%$ of the participants think they will need help of technical person to use the website.

Table 2 Usability system scale results, 2018

\begin{tabular}{|c|c|c|c|c|c|c|}
\hline \multirow[t]{2}{*}{$\begin{array}{l}\mathbf{S} / \\
\mathbf{N}\end{array}$} & \multirow[t]{2}{*}{$\begin{array}{l}\text { Post Study usability questionnaire (System } \\
\text { Usability Scale) }\end{array}$} & \multirow{2}{*}{$\begin{array}{l}\text { Strong } \\
\text { agree } \\
4\end{array}$} & Agree & Disagree & \multirow{2}{*}{$\begin{array}{l}\begin{array}{l}\text { Strong } \\
\text { disagree }\end{array} \\
1\end{array}$} & \multirow{2}{*}{$\begin{array}{l}\text { Percentage } \\
\text { agree } \\
\%\end{array}$} \\
\hline & & & 3 & 2 & & \\
\hline 1 & $\begin{array}{l}\text { I think I would like to use this system } \\
\text { frequently }\end{array}$ & 3 & 1 & 1 & 0 & $80 \%$ \\
\hline 2 & I thought the system was easy to use & 2 & 1 & 1 & 1 & $60 \%$ \\
\hline 3 & $\begin{array}{l}\text { I would imagine that most people would learn } \\
\text { to use this system very quickly }\end{array}$ & 0 & 3 & 2 & 0 & $60 \%$ \\
\hline 4 & $\begin{array}{l}\text { I will need the help of a technical person to be } \\
\text { able to use the system }\end{array}$ & 1 & 1 & 2 & 1 & $40 \%$ \\
\hline 5 & $\begin{array}{l}\text { I believe I could become productive quickly } \\
\text { using this system. }\end{array}$ & 2 & 1 & 1 & 1 & $60 \%$ \\
\hline 6 & $\begin{array}{l}\text { I found various functions on the system were } \\
\text { well integrated. }\end{array}$ & 0 & 3 & 2 & 0 & $60 \%$ \\
\hline 7 & I would recommend the system to a friend & 3 & 2 & 0 & 0 & $100 \%$ \\
\hline
\end{tabular}

\section{Discussion}

In task number two (find advertisement) and three (find more info. about advertised products), words used to labels the buttons were straight forward, no complex words hence no ambiguity. This is a relatedness experience, and it feels good to use system like this to accomplish your goals. For example in this work, website has been used as instrument to create this experience, but the positive emotion and the meaning are induced through the fulfilment of a universal inner need [16, 21]. This indicates that users were emotionally satisfied when performing these tasks and their expectation was met. The implication of this is that users will not abandon the website, they will come back and use it to find market information and advertise their poultry and poultry products. This will improve competitiveness in poultry farming.

In task number one (create account) and four (try selling 20 eggs), users found it difficult to perform the two tasks because of the following reasons; users found that "register" word was confusing. They expect "create account" word instead of "register" word. Also login and register was not clearly differentiated. Checkout word was confusing most of the user expected something like "payment" instead of checkout. The website did not show up the shipping price when someone mentioned the destination place. Mpesa and tigopesa as local payment method there but not working. Some buttons were not working at all. This indicates bad user experience that may lead to lack of user satisfaction.

\section{Conclusion}

The primary focus of this work was to emphasize the consideration of user experience design when developing livestock (poultry) information systems in Tanzania in order to achieve usefulness and appeal. Web based platform for market linkages was developed and user experience was tested.

The findings indicated that most of the users found the system was easy to use and they will need to use the system. Furthermore users were emotionally happy when performing some of the tasks because users understood what the website was for and the interface was clear.

But also users were anxious and disappointed when performing some of the tasks as described in detail on section 3. It was discovered users spent a lot of time 
and found it difficult to perform the tasks because the interface was not clear and some of the words used to label the buttons were confusing and not straightforward.

The importance of these results is that, it is now clear that we need to make changes based on these findings in an iterative design process to achieve great user experience hence emotional satisfaction. The implication of this is that the system will be abandoned. The practical contribution of this study is that, the more you integrate experiences in the entire process of designing, acquiring, testing and integrating a product or service the more you achieve great user experience especially in the context of websites and mobile application and users should be put at the centre. Think about all the stages of website development, because website is more than a product and it should mean integrating a set of experiences.

Therefore this study recommends that, government together with higher learning institution in Tanzania should provide support to improve the learning of user experience design to students who study in this area such as by integrating it into the curriculum for Computer Science courses. In addition when it comes to websites, developers should understand that user experience design is not just about one thing user interface or performance. It is about integrating all elements which work together to impact user's perception on the websites.

\section{Acknowledgment}

The authors acknowledge DAAD for funding this research and anonymous reviewers for their contribution.

\section{Conflicts of interest}

We confirm that the manuscript has been read and approved by all named authors and we have no conflict of interest to declare.

\section{References}

[1] Chawla S, Srivastava S, Bedi P. Improving the quality of web applications with web specific goal driven requirements engineering. International Journal of System Assurance Engineering and Management. 2017; 8(1):65-77.

[2] Panthi V, Mohapatra DP. An approach for dynamic web application testing using MBT. International Journal of System Assurance Engineering and Management. 2017; 8(2):1704-16.

[3] Mussa M, Kipanyula MJ, Angello C, Sanga CA. Evaluation of livestock information network knowledge system (LINKS) based on user satisfaction. International Journal of Information and
Communication Technology Research. 2016; 6(8):115-30.

[4] Kalimullah K, Sushmitha D. Influence of design elements in mobile applications on user experience of elderly people. Procedia Computer Science. 2017; 113:352-9.

[5] Hellweger S, Wang X. What is user experience really: towards a UX conceptual framework. arXiv preprint arXiv:1503.01850. 2015.

[6] Hui SL, See SL. Enhancing user experience through customization of UI design. Procedia Manufacturing. 2015; 3:1932-7.

[7] Buley L. The user experience team of one: a research and design survival guide. Rosenfeld Media; 2013.

[8] http://www.infragistics.com/media/335732/the_busine ss_value_of_user_experience-3.pdf. Accessed 20 July 2018.

[9] https://www.csun.edu/sites/default/files/User\%20Expe rience $\% 20 \mathrm{in} \% 20 \mathrm{Web} \% 20$ Development.pdf. Accessed 03 July 2018.

[10] http://www.tirop.com/up/ux-design-for-startupsmarcin-treder.pdf. Accessed 20 July 2018.

[11] https://vlgux.com/deliverables/ro-why.pdf. Accessed 03 July 2018.

[12] Islam MK, Uddin M F, Alam MM. Challenges and prospects of poultry industry in Bangladesh. European Journal of Business and Management. 2014; 6(7):11627.

[13] Hamra CF. An assessment of the potential profitability of poultry farms: a broiler farm feasibility case study. Doctoral Dissertation, University of Tennessee at Martin. 2010.

[14] Sundberg HR. The role of user experience in a business-to-business context.Tampere University of Technology. 2015.

[15] Hartson R, Pyla PS. The UX book: process and guidelines for ensuring a quality user experience. Elsevier; 2012.

[16] http://web.uchile.cl/DctosIntranet/05UsabilidadExperi enciaUsuario/BuenasPracticas/BestPracticesUserExpe rience.pdf. Accessed 24 July 2018.

[17] Junior M, De Assis V, Gomes JC. Benefits and success factors of open-source web services development platforms for small software houses. Journal of Information Systems and Technology Management. 2012; 9(3):585-606.

[18] Vinay, Satinder. Study of content management system: wordpress. International Journal of Advance Research in Science and Engineering. 2015; 4(1):4126.

[19] Fernandes S, Vidyasagar A. Digital marketing and wordpress. Indian Journal of Science and Technology. 2015; 8(S4):61-8.

[20] https://www.nngroup.com/articles/usability-101introduction-to-usability/. Accessed 24 July 2018.

[21] Hassenzahl M. User experience and experience design. The Encyclopedia of Human-Computer Interaction. 2013. 


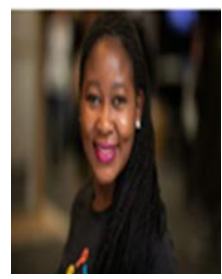

Cesilia Mambile is a Masters candidate in Information Communication Science and Engineering, Specializing in Information Technology Systems Development and Management at Nelson Mandela African Institution of Science and Technology, Arusha Tanzania. She was at DHBW Heidenheim Germany for a period of three months (March up to May 2018), for short term research on a DAAD Scholarship and gained knowledge on system design and user experience design. Currently she is working with Tanzania Public Service College, Tanga campus as Admission and Examination officer since February 2015. She graduated her BSc in Information Technology at The Institute of Finance Management, Dar es Salaam Tanzania in 2011.

Email: mambile30@gmail.com

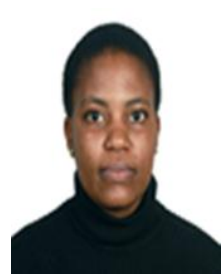

Dina Machuve is a lecturer and researcher at the Nelson Mandela African Institution of Science and Technology (NM-AIST) in Tanzania. She graduated with a $\mathrm{PhD}$ in Information and Communication Science and Engineering from NMAIST in 2016, and with a MS in Electrical Engineering from Tennessee Technological University, USA in 2008 and BSc Electrical Engineering degree from University of Dar es Salaam in 2001. She serves in the organizing committee of Data Science Africa, an organization that runs an annual data science and machine learning summer school and workshop in Africa. Her research interests are Data Science, Bioinformatics, Agriculture Informatics on Food Value Chains and STEM Education in schools.

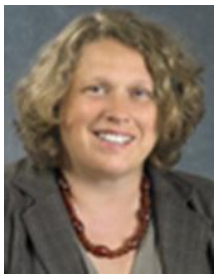

Sabine Moebs is a professor at DHBW Heidenheim, Germany and manager of the AR_DL_UX-Lab, offering a space for open innovation in Augmented Reality, Digital Learning, UX and its accessibility. Her special interest is EUAfrica research collaboration, currently working with partners in Tanzania, Uganda and South Africa and dual university models. She holds a $\mathrm{PhD}$ in Electronic Engineering from Dublin City University in the area of Adaptive Multimedia eLearning as well as an MSc in Computer Science. 